\title{
The Significance of Preoperative Computed Tomography for Predicting Optimal Cytoreduction in Advanced Ovarian Cancer
}

\author{
Stellenwert der präoperativen Computertomografie \\ für die Prädiktion einer optimalen Zytoreduktion beim \\ fortgeschrittenen Ovarialkarzinom
}

(C) (9) $\ominus$

Authors

Angrit Stachs ${ }^{1}$, Karen Engel ${ }^{2}$, Johannes Stubert ${ }^{3}$, Toralf Reimer $^{3}$, Bernd Gerber ${ }^{3}$, Max Dieterich ${ }^{3}$

Affiliations

1 Gynäkologische Radiologie, University of Rostock, Rostock, Germany

2 University of Rostock, Rostock, Germany

3 Universitätsfrauenklinik, University of Rostock, Rostock, Germany

Key words

ovarian cancer, computed tomography, R0 resection, debulking surgery

Schlüsselwörter

Ovarialkarzinom, Computertomografie, R0-Resektion, Debulking-Operation

received

accepted after revision

21.7.2020

Bibliography

DOI https://doi.org/10.1055/a-1226-6505

Geburtsh Frauenheilk 2020; 80: 915-923 @ Georg Thieme

Verlag KG Stuttgart · New York | ISSN 0016-5751

Correspondence

PD Dr. med. Angrit Stachs

Abteilung für Gynäkologische Radiologie der

Universitätsfrauenklinik am Klinikum Südstadt

Südring 81, 18059 Rostock, Germany

angrit.stachs@uni-rostock.de

$\Theta$

Deutsche Version unter:

https://doi.org/10.1055/a-1226-6505

\section{ABSTRACT}

Introduction Optimal cytoreduction is the most important prognostic factor in advanced ovarian cancer. Although staging and assessment of operability are made by exploratory surgery, preoperative computed tomography (CT) of the abdomen is regarded as standard. The aim of this study was to examine various $\mathrm{CT}$ parameters with regard to prediction of optimal cytoreduction.

Patients and Methods The retrospective study included 131 patients with ovarian cancer newly diagnosed between 2010 and 2014. Of these, $n=36$ with FIGO stage I to IIB were excluded from the study. A preoperative abdominal CT was available for $n=75$ of the 95 patients with FIGO stage IIC to IV. The CT scans underwent blinded review. The 11 evaluated CT parameters were examined by means of $X^{2}$ test and logistic regression analysis with regard to the endpoints of macroscopic residual tumour and residual tumour $>1 \mathrm{~cm}$. Survival analyses used the Kaplan-Meier method and log rank test.

Results Of 75 patients, 28 (37.3\%) had complete tumour resection and 26 (34.7\%) had residual tumour $\leq 1 \mathrm{~cm}$. Residual tumours $>1 \mathrm{~cm}$ were found in 21 (28\%) patients, five of which were not resectable. Overall survival with residual tumour $>1 \mathrm{~cm}$ differed significantly from the group with no macroscopic residual tumour $(p=0.003)$ and with residual tumour $\leq 1 \mathrm{~cm}(p=0.04)$. The CT parameters tumour foci in the diaphragm, mesocolon, greater omentum and peritoneum as well as ascites correlated with macroscopic residual tumour. In the multivariate logistic regression analysis only the CT parameter intraparenchymal liver metastasis was statistically significant with regard to prediction of suboptimal tumour resection (> $1 \mathrm{~cm})(\mathrm{OR} 8.04$; $95 \% \mathrm{Cl} 1.57-42.4 ; \mathrm{p}=0.0134)$. The sensitivity, specificity, PPV and NPV were 37.5, 89.7, 66.7 and $72.2 \%$.

Conclusion Although risk parameters for suboptimal tumour reduction can be identified by $\mathrm{CT}$ of the abdomen, surgical exploration with histological confirmation of the diagnosis is essential because of the poor diagnostic accuracy.

\section{ZUSAMMENFASSUNG}

Einleitung Eine optimale Zytoreduktion ist der wichtigste Prognosefaktor beim fortgeschrittenen Ovarialkarzinom. Obwohl Stadieneinteilung und Einschätzung der Operabilität durch Explorativ-Operation erfolgen, gilt die präoperative Computertomografie (CT) des Abdomens als Standard. Ziel 
dieser Studie ist die Überprüfung verschiedener CT-Parameter hinsichtlich der Prädiktion einer optimalen Zytoreduktion.

Patienten und Methoden In die retrospektive Studie wurden 131 Patientinnen mit zwischen 2010 bis 2014 neu diagnostiziertem Ovarialkarzinom aufgenommen. Davon wurden $\mathrm{n}=36 \mathrm{im}$ FIGO-Stadium I bis IIB aus der Studie ausgeschlossen. Von den 95 Patientinnen mit FIGO-Stadium IIC bis IV lagen bei $n=75$ präoperative CT-Abdomen vor. Die CT-Scans wurden einem verblindeten Review unterzogen. Die evaluierten 11 CT-Parameter wurden mittels $X^{2}$-Test und logistischer Regressionsanalyse hinsichtlich der Endpunkte makroskopischer Tumorrest sowie Tumorrest $>1 \mathrm{~cm}$ überprüft. Überlebensanalysen erfolgten mittels Kaplan-Meier-Methode und Log-Rank-Test.

Ergebnisse Von 75 Patientinnen hatten 28 (37,3\%) eine vollständige Tumorresektion und 26 (34,7\%) Tumorreste $\leq 1 \mathrm{~cm}$. Tumorreste $>1 \mathrm{~cm}$ fanden sich bei 21 Patientinnen (28\%), da- von waren 5 nicht resektabel. Das Gesamtüberleben bei Tumorrest $>1 \mathrm{~cm}$ unterschied sich signifikant von der Gruppe mit makroskopischer Tumorfreiheit $(p=0,003)$ bzw. Tumorrest $\leq 1 \mathrm{~cm}(p=0,04)$. Die CT-Parameter Tumorherde am Diaphragma, Mesokolon, Omentum majus, Peritoneum sowie Aszites korrelierten mit makroskopischem Tumorrest. In der multivariaten logistischen Regressionsanalyse war lediglich hinsichtlich der Prädiktion einer suboptimalen Tumorresektion $(>1 \mathrm{~cm})$ der CT-Parameter intraparenchymatöse Lebermetastase statistisch signifikant (OR 8,04; 95\%-KI 1,57-42,4; $\mathrm{P}=0,0134$ ). Sensitivität, Spezifität, PPV und NPV betragen $37,5,89,7,66,7$ und $72,2 \%$.

Schlussfolgerung Obwohl mittels CT Abdomen Risikoparameter für suboptimale Tumorreduktion identifizierbar sind, ist wegen der geringen diagnostischen Genauigkeit die chirurgische Exploration mit histologischer Diagnosesicherung unverzichtbar.

\section{Introduction}

In 2016, ovarian cancer (OC) was responsible for one third of gynaecological cancers in Germany, with 7350 new cases, and for half of gynaecological cancer deaths, with approximately 5500 deaths. The prognosis is relatively poor because of late diagnosis (76\% in stage III and IV). The relative 5-year survival rate is currently $43 \%$ [1]. Besides tumour stage, complete surgical tumour resection is considered to be the most important prognostic parameter for disease-free and overall survival. According to du Bois (2009), the effect was much more pronounced when there was no macroscopic tumour than after so-called optimal tumour reduction when residual tumours up to $10 \mathrm{~mm}$ remain in situ [2]. If no optimal cytoreduction is possible, the benefit of neoadjuvant chemotherapy followed by interval surgery was investigated in various studies [3-7]. Neoadjuvant chemotherapy does not appear to confer any benefit with regard to overall survival, so primary debulking surgery followed by six cycles of platinum-containing chemotherapy is regarded as standard [8]. Recent data from the prospective randomised Desktop III study on secondary cytoreduction for recurrent $\mathrm{OC}$ show that patients in whom complete tumour resection was possible in a secondary operation also have median overall survival that is more than 12 months longer [9].

Computed tomography (CT) of the abdomen as part of preoperative staging enables assessment of para-aortic lymph nodes, detection of liver metastases and of pleural effusions [10,11]. As regards assessment of optimal cytoreduction, however, the data are controversial. While predominantly retrospective studies provide evidence that $\mathrm{CT}$ has high diagnostic reliability with regard to predicting optimal or suboptimal tumour reduction [12-16], two multicentre studies do not confirm these data $[17,18]$. All studies refer to residual tumour $\leq 1 \mathrm{~cm}$ as the definition of optimal tumour reduction. The primary aim of this study was therefore to evaluate preoperative CT with regard to the endpoint no macroscopic tumour vs. macroscopic residual tumour. The secondary study aims were analysis of the CT parameters with regard to suboptimal tumour reduction (residual tumour $>1 \mathrm{~cm}$ ), the influence of residual tumour on overall survival and prediction of para-aortic lymph node metastases by means of CT.

\section{Patients and Methods}

The retrospective study included all patients with a primary diagnosis of advanced OC at Rostock University Women's Clinic from 2010 to 2014. Patients with primary peritoneal cancer and tubal cancer were also included. Patients with non-epithelial ovarian tumours and tumours of borderline malignancy were excluded. Clinical data and histopathological features were obtained from the patients' files and the Mecklenburg-Western Pomerania clinical cancer registry.

\section{Evaluation of the CT scans}

The CT scans, stored in DICOM format, were reviewed by a radiologist experienced in oncology who did not know the surgical outcome. Based on the study by Axtell et al. (2007) the following CT parameters were recorded: metastases in the diaphragm $>2 \mathrm{~cm}$, metastases in the mesocolon $>2 \mathrm{~cm}$, involvement of the greater omentum, suprarenal lymph nodes $>1 \mathrm{~cm}$, infrarenal lymph nodes $>2 \mathrm{~cm}$, diffuse peritoneal thickening, pleural effusion, presence of ascites, peritoneal metastases $>2 \mathrm{~cm}$, intraparenchymal liver metastases and involvement of the inguinal canal [18].

\section{Surgical procedure}

All patients had surgical exploration by one of two gynaecologists who subspecialise in gynaecological oncology with the aim of maximal cytoreduction. In accordance with the guidelines valid prior to publication of the LION (Lymphadenectomy In Ovarian Neoplasms) study [19], systematic pelvic and para-aortic lymph node excision (LNE) was performed in patients when $\mathrm{R} 0$ resection was pursued, and enlarged lymph nodes were removed otherwise. No patient had neoadjuvant chemotherapy. The surgeon's assessment regarding the operation outcome acted as diagnostic reference. Four categories were recorded initially: no macroscopic tumour, 1-10 mm tumour resection, tumour debulking with re- 


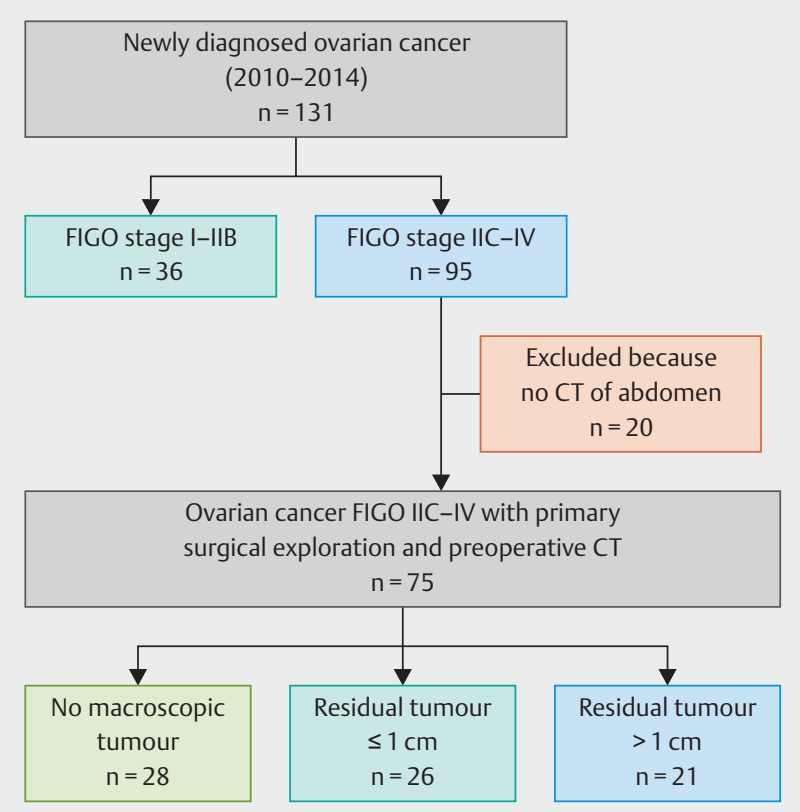

- Fig. 1 Study population flow chart.

sidual tumour $>1 \mathrm{~cm}$, non-resectable. For the statistical analysis, these were combined into the following groups: no macroscopic tumour vs. macroscopic residual tumour and residual tumour $\leq 1 \mathrm{~cm}$ vs. $>1 \mathrm{~cm}$.

\section{Statistical analysis}

Statistical analysis was performed with SPSS Statistics 25 (IBM Deutschland $\mathrm{GmbH}$, Ehningen). Survival analyses were carried out using the Kaplan-Meier method and log rank test.

For group comparisons we used the $x^{2}$ test for categorical variables and Fisher's exact test when the case number was small. Quantitative characteristics such as age, body mass index (BMI) and Karnofsky index were combined into categories according to clinical relevance. The tumour marker CA 12-5 and serum albumin were not included because of a large number of missing values, and information about the BRCA status was also omitted as this was available only in isolated cases in the cohort. All variables with $p<0.2$ in univariate analysis were included in the multivariance analysis. Binary logistic regression of independent variables, which generates the adjusted odds ratio (aOR) and corresponding p-values and $95 \%$ confidence intervals $(95 \% \mathrm{Cl})$ served as model. The significance level was set at $p<0.05$. The diagnostic accuracy in the form of sensitivity, specificity, positive predictive value (PPV) and negative predictive value (NPV) were obtained for predictive $C T$ parameters identified as independent.

\section{Results}

\section{Patient characteristics}

Out of 131 patients, $\mathrm{n}=36$ had International Federation of Gynaecology and Obstetrics (FIGO classification 1988) stage I-IIB dis-
- Table 1 Patient characteristics $(n=75)$.

\begin{tabular}{|c|c|c|}
\hline & n & $\%$ \\
\hline \multicolumn{3}{|l|}{ Age } \\
\hline . $<75$ years & 70 & 93.3 \\
\hline . $\geq 75$ years & 5 & 6.7 \\
\hline \multicolumn{3}{|l|}{ BMI kg/m² } \\
\hline . $<30 \mathrm{~kg} / \mathrm{m}^{2}$ & 48 & 64.0 \\
\hline - $\geq 30 \mathrm{~kg} / \mathrm{m}^{2}$ & 27 & 36.0 \\
\hline \multicolumn{3}{|l|}{ ASA score } \\
\hline . $1-2$ & 47 & 62.6 \\
\hline .3 & 28 & 37.4 \\
\hline \multicolumn{3}{|l|}{ Karnofsky index (\%) } \\
\hline.$>70$ & 65 & 86.7 \\
\hline.$\leq 70$ & 10 & 13.3 \\
\hline \multicolumn{3}{|l|}{ FIGO stage* } \\
\hline - IIC & 12 & 16.0 \\
\hline . IIIA & 2 & 2.7 \\
\hline - IIIB & 6 & 8.0 \\
\hline . IIIC & 33 & 44.0 \\
\hline . IV & 22 & 29.3 \\
\hline \multicolumn{3}{|l|}{ Histological subtype } \\
\hline - serous-papillary, high-grade & 44 & 58.7 \\
\hline - serous-papillary, low-grade & 9 & 12.0 \\
\hline - endometrioid & 11 & 14.7 \\
\hline - mucinous & 2 & 2.7 \\
\hline - clear cell & 5 & 6.7 \\
\hline - undifferentiated & 4 & 5.2 \\
\hline \multicolumn{3}{|l|}{ Type of primary operation } \\
\hline - LSC $\rightarrow$ laparotomy (one-stage) & 15 & 20.0 \\
\hline - LSC $\rightarrow$ laparotomy (two-stage) & 10 & 13.3 \\
\hline - Laparotomy & 50 & 66.7 \\
\hline \multicolumn{3}{|l|}{ Bowel resection } \\
\hline - no & 49 & 65.3 \\
\hline - yes & 26 & 34.7 \\
\hline \multicolumn{3}{|l|}{ Postoperative residual tumour } \\
\hline $.0 \mathrm{~mm}$ & 28 & 37.3 \\
\hline . $1-10 \mathrm{~mm}$ & 26 & 34.7 \\
\hline . >10 mm & 16 & 21.3 \\
\hline - not resectable & 5 & 6.7 \\
\hline
\end{tabular}

ease so these were excluded from further analysis. Of the 95 patients with FIGO stage IIC to IV no preoperative CT of abdomen was available in DICOM format for 20 patients. In the remaining 75 patients no macroscopic tumour was achieved in $37.3 \%$, residual tumours from $1-10 \mathrm{~mm}$ were present in $34.7 \%$, residual tumours $>10 \mathrm{~mm}$ remained in $21.3 \%$ and the tumour was not resectable in 5 patients $(6.7 \%)$ ( $\bullet$ Fig. 1$)$. The mean age was 63 years (min. 34, max. 81 years, SD 10.4 years). The mean BMI 


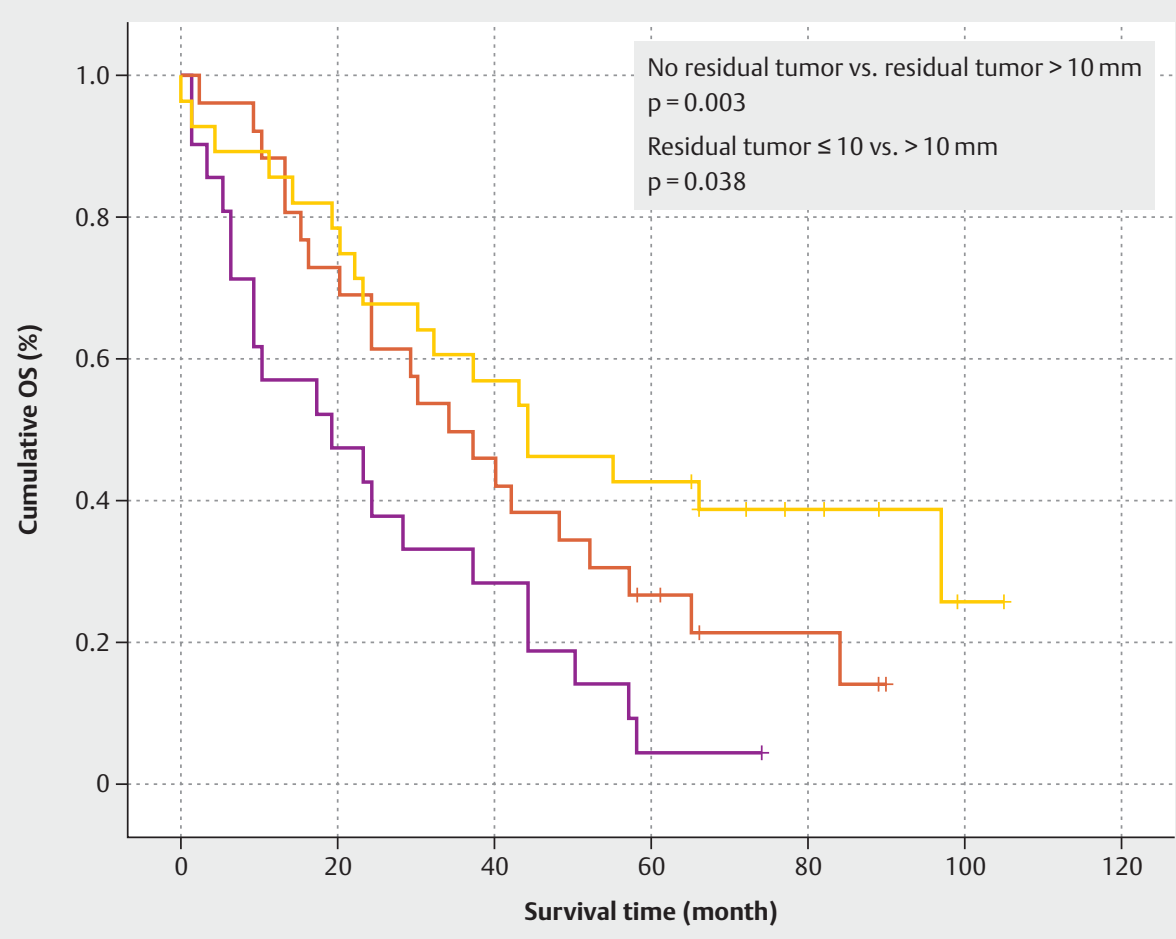

\section{Surgical outcome}

_ No residual tumor

Residual tumor $1-10 \mathrm{~mm}$

Residual tumor $>10 \mathrm{~mm}$

++ Censored

- Fig. 2 Cumulative overall survival on ovarian cancer stage IIC-IV $(n=75)$ depending on the size of the postoperative residual tumour.

was $28 \mathrm{~kg} / \mathrm{m}^{2}$, and $36 \%$ of the women were obese (BMI $\geq 30 \mathrm{~kg} /$ $\mathrm{m}^{2}$ ). $13.3 \%$ of the women had a Karnofsky index $<70 \%$. According to the American Society of Anaesthetists (ASA) classification $37.3 \%$ had a score of 3 . On histopathology, high-grade serous papillary OC was found in $58.7 \%$, while other types occurred much more seldom: low-grade serous OC in $12 \%$, endometrioid OC in $14.6 \%$, clear cell OC in $6.7 \%$ and undifferentiated OC in $5.3 \%$. The operative procedure consisted of primary laparotomy in $66.7 \%$, laparoscopy (LSC) with conversion to laparotomy (onestage) in $20 \%$ and laparoscopy with subsequent laparotomy (twostage procedure within 10 days after LSC) in $13.3 \%$. In $34.7 \%$ of the women, a multivisceral operation with partial bowel resection was performed ( $\triangleright$ Table $\mathbf{1})$.

\section{Survival analysis}

The cumulative 5 -year overall survival rate was $42.9 \%$ for patients with no macroscopic tumour, $26.9 \%$ with macroscopic residual tumour $1-10 \mathrm{~mm}$ and $4.8 \%$ with residual tumour $>10 \mathrm{~mm}$. The median overall survival was significantly higher at 44 months with no macroscopic tumour than with residual tumour $1-10 \mathrm{~mm}$ (34 months) and reached 19 months with residual tumour $>10 \mathrm{~mm}$ (no residual tumour vs. residual tumour $>10 \mathrm{~mm}$, $\mathrm{p}=0.003$; residual tumour $1-10$ vs. $>10 \mathrm{~mm}, \mathrm{p}=0.038)$ ( $>$ Fig. 2 ).

\section{CT parameters}

Diffuse peritoneal thickening was described preoperatively in 47/ $75(62.7 \%)$ patients, the CT report found involvement of the greater omentum in $34.7 \%$, pleural effusion and ascites were each described in $32 \%$, and metastases in the mesocolon $>2 \mathrm{~cm}$ were found in $29.3 \%$. Suprarenal lymph nodes $>1 \mathrm{~cm}$ were found in $20 \%$ and infrarenal lymph nodes $>2 \mathrm{~cm}$ in $18.7 \%$. Intraparenchymal liver metastases were detected in $9 / 75$ (12\%). All of the five patients with non-resectable tumour had a pleural effusion and four had diffuse peritoneal thickening and metastases in the mesocolon $>2 \mathrm{~cm}$ ( $\triangleright$ Table 2 ).

\section{Macroscopic residual tumour vs. no macroscopic tumour}

When the groups macroscopic residual tumour $(n=47)$ vs. no residual tumour $(n=28)$ were compared using univariate analysis, the high-grade serous papillary OC histopathological subtype increased the risk, while a $\mathrm{BMI} \geq 30 \mathrm{~kg} / \mathrm{m}^{2}$ tended to be associated with a lower risk of residual tumour (OR 0.38; 95\% Cl 0.14-1.02; $\mathrm{p}=0.051)$. The following $C T$ parameters were associated with a significantly increased risk of macroscopic residual tumour: diaphragm metastases $>2 \mathrm{~cm}(p=0.002)$, mesocolon metastases $>2 \mathrm{~cm}(p=0.004)$, metastases in the greater omentum $(p=0.007)$, peritoneal metastases $>2 \mathrm{~cm} \quad(p=0.03)$, ascites $(p=0.002)$ and diffuse peritoneal thickening $(p<0.001)$. In the multivariate logistic regression, however, no CT feature was found to be an independent parameter for the endpoint macroscopic residual tumour; only the histopathological subtype high-grade serous papillary OC (aOR 5.5; 95\% Cl 1.48-20.6; $\mathrm{p}=0.011$ ) was identified as an independent parameter ( $\vee$ Table 3 ).

\section{Residual tumour $>10 \mathrm{~mm}$ vs. $\leq 10 \mathrm{~mm}$}

From the clinical and histopathological parameters no predictor for suboptimal tumour resection (residual tumour $>10 \mathrm{~mm}$ ) could 
- Table 2 Various CT parameters found with ovarian cancer FIGO stage IIC-IV $(n=75)$ in relation to the debulking surgery outcome.

\begin{tabular}{|c|c|c|c|c|c|}
\hline \multirow[t]{2}{*}{ Parameter } & \multirow{2}{*}{$\begin{array}{l}\text { Total } \\
n=75\end{array}$} & \multicolumn{4}{|c|}{ Postoperative residual tumour } \\
\hline & & $\begin{array}{l}0 \\
n=28\end{array}$ & $\begin{array}{l}1-10 \mathrm{~mm} \\
\mathrm{n}=26\end{array}$ & $\begin{array}{l}>10 \mathrm{~mm} \\
\mathrm{n}=16\end{array}$ & $\begin{array}{l}\text { Not resectable } \\
n=5\end{array}$ \\
\hline Diaphragm $\geq 2 \mathrm{~cm}$ & $15(20.0 \%)$ & 1 & 8 & 5 & 1 \\
\hline Mesocolon $\geq 2 \mathrm{~cm}$ & $22(29.3 \%)$ & 2 & 11 & 5 & 4 \\
\hline Greater omentum & $26(34.7 \%)$ & 4 & 12 & 8 & 2 \\
\hline Suprarenal LN > $1 \mathrm{~cm}$ & $15(20.0 \%)$ & 4 & 5 & 6 & 0 \\
\hline Infrarenal $L N \geq 2 \mathrm{~cm}$ & $14(18.7 \%)$ & 2 & 7 & 3 & 2 \\
\hline Diffuse peritoneal thickening & $47(62.7 \%)$ & 10 & 21 & 12 & 4 \\
\hline Pleural effusion & $24(32.0 \%)$ & 15 & 23 & 13 & 5 \\
\hline Ascites & $24(32.0 \%)$ & 6 & 9 & 7 & 2 \\
\hline Peritoneal metastases $\geq 2 \mathrm{~cm}$ & $14(18.7 \%)$ & 1 & 8 & 5 & 0 \\
\hline Intraparenchymal liver metastases & $9(12.0 \%)$ & 2 & 1 & 6 & 0 \\
\hline Involvement of the inguinal canal & $9(12.0 \%)$ & 4 & 3 & 2 & 0 \\
\hline
\end{tabular}

- Table 3 Univariate and multivariate logistic regression analysis of clinical, histopathological and radiological features with regard to the risk of macroscopic residual tumour vs. no macroscopic tumour.

\begin{tabular}{|c|c|c|c|c|c|c|}
\hline \multirow[b]{2}{*}{ Variable } & \multicolumn{3}{|c|}{ Univariate logistic regression } & \multicolumn{3}{|c|}{ Multivariate logistic regression } \\
\hline & OR & $95 \% \mathrm{Cl}$ & p-value & $\mathrm{aOR}$ & $95 \% \mathrm{Cl}$ & p-value \\
\hline Age $\geq 70$ years & 1.76 & $0.55-5.60$ & 0.34 & & & \\
\hline $\mathrm{BMI} \geq 30 \mathrm{~kg} / \mathrm{m}^{2}$ & 0.38 & $0.14-1.02$ & 0.054 & 0.40 & $0.12-1.3$ & 0.13 \\
\hline ASA stage 3 & 1.03 & $0.37-2.85$ & 0.95 & & & \\
\hline Karnofsky index $\leq 70 \%$ & 0.55 & $0.14-2.09$ & 0.38 & & & \\
\hline Serous papillary, high-grade & 8.18 & $2.82-23.67$ & 0.0001 & 5.51 & $1.48-20.56$ & 0.011 \\
\hline \multicolumn{7}{|l|}{ CT parameter } \\
\hline - Diaphragm $\geq 2 \mathrm{~cm}$ & 11.46 & $1.42-92.7$ & 0.022 & 3.08 & $0.24-40.2$ & 0.39 \\
\hline - Mesocolon $\geq 2 \mathrm{~cm}$ & 9.63 & $2.04-45.3$ & 0.004 & 4.22 & $0.60-29.7$ & 0.15 \\
\hline - Greater omentum & 5.28 & $1.58-17.6$ & 0.007 & 2.97 & $0.48-18.4$ & 0.24 \\
\hline - Suprarenal $\mathrm{LN} \geq 2 \mathrm{~cm}$ & 1.62 & $0.46-5.76$ & 0.44 & & & \\
\hline - Infrarenal LN $\geq 2 \mathrm{~cm}$ & 4.46 & $0.92-21.6$ & 0.064 & & & \\
\hline - Diffuse peritoneal thickening & 6.66 & $2.35-18.9$ & $<0.001$ & 3.76 & $0.78-18.0$ & 0.098 \\
\hline - Pleural effusion & 2.28 & $0.77-6.68$ & 0.135 & & & \\
\hline - Ascites & 5.92 & $1.9-18.4$ & 0.002 & 2.07 & $0.36-12.0$ & 0.42 \\
\hline - Peritoneal metastases $\geq 2 \mathrm{~cm}$ & 10.32 & $1.27-83.9$ & 0.029 & 0.35 & $0.02-6.14$ & 0.47 \\
\hline - Inguinal canal & 0.71 & $0.175-2.92$ & 0.64 & & & \\
\hline - Intraparenchymal liver metastases & 2.27 & $0.44-11.8$ & 0.33 & & & \\
\hline
\end{tabular}

be identified; the Karnofsky index $\leq 70 \%$ (aOR 5.96; 95\% Cl 0.9935.7; $\mathrm{p}=0.051$ ) was just below the level of significance. Of the CT parameters, intraparenchymal liver metastases were associated with a significantly increased risk of residual tumour $>10 \mathrm{~mm}$ (aOR 8.04; 95\% Cl 1.53-42.2; $\mathrm{p}=0.014$ ). All other CT parameters showed no significant differences when the groups were com- pared ( $\triangleright$ Table 4 ). The diagnostic validity of CT with regard to suboptimal tumour resection thus reaches a sensitivity of $37.5 \%$ (95\% Cl 15.2-64.6) with a specificity $89.7 \%$ (95\% Cl 72.6-97.8), the positive predictive value (PPV) is $66.7 \%(95 \% \mathrm{Cl} 36.6-87.4)$ and the negative predictive value (NPV) is $72.2 \%$ (95\% Cl 63.6-79.5). The accuracy of the test is $71.1 \%(95 \% \mathrm{Cl} 55.7-83.6)$. 
- Table 4 Univariate and multivariate logistic regression analysis of clinical, histopathological and radiological features with regard to the risk of suboptimal tumour reduction (residual tumour $>10 \mathrm{~mm}$ vs. $\leq 10 \mathrm{~mm}$ ).

\begin{tabular}{|c|c|c|c|c|c|c|}
\hline \multirow[b]{2}{*}{ Variable } & \multicolumn{3}{|c|}{ Univariate logistic regression } & \multicolumn{3}{|c|}{ Multivariate logistic regression } \\
\hline & OR & $95 \% \mathrm{Cl}$ & p-value & aOR & $95 \% \mathrm{Cl}$ & p-value \\
\hline Age $\geq 70$ years & 1.63 & $0.58-4.61$ & 0.36 & & & \\
\hline $\mathrm{BMI} \geq 30 \mathrm{~kg} / \mathrm{m}^{2}$ & 1.5 & $0.53-4.21$ & 0.44 & & & \\
\hline ASA stage 3 & 2.22 & $0.752-6.55$ & 0.15 & & & \\
\hline Karnofsky index $\leq 70 \%$ & 3.06 & $0.78-11.96$ & 0.11 & 5.96 & $0.99-35.7$ & 0.051 \\
\hline Serous papillary, high-grade & 2.2 & $0.73-6.39$ & 0.16 & 1.8 & $0.51-6.48$ & 0.36 \\
\hline \multicolumn{7}{|l|}{ CT parameter } \\
\hline - Diaphragm $\geq 2 \mathrm{~cm}$ & 2.0 & $0.61-6.6$ & 0.25 & & & \\
\hline - Mesocolon $\geq 2 \mathrm{~cm}$ & 2.36 & $0.82-6.87$ & 0.11 & 2.15 & $0.54-8.6$ & 0.28 \\
\hline - Greater omentum & 2.16 & $0.77-6.09$ & 0.15 & 0.98 & $0.26-3.75$ & 0.98 \\
\hline - Suprarenal LN $\geq 2 \mathrm{~cm}$ & 1.56 & $0.46-5.36$ & 0.48 & & & \\
\hline - Infrarenal LN $\geq 2 \mathrm{~cm}$ & 1.56 & $0.46-5.36$ & 0.48 & & & \\
\hline - Diffuse peritoneal thickening & 2.37 & $0.76-7.42$ & 0.14 & 1.26 & $0.3-5.37$ & 0.75 \\
\hline - Pleural effusion & 1.95 & $0.68-5.57$ & 0.21 & & & \\
\hline - Ascites & 2.53 & $0.65-9.79$ & 0.18 & 1.35 & $0.25-7.18$ & 0.73 \\
\hline - Peritoneal metastases $\geq 2 \mathrm{~cm}$ & 1.56 & $0.46-5.36$ & 0.48 & & & \\
\hline - Inguinal canal & 0.71 & $0.13-3.72$ & 0.68 & & & \\
\hline - Intraparenchymal liver metastases & 6.8 & $1.52-30.5$ & 0.012 & 8.04 & $1.53-42.2$ & 0.014 \\
\hline
\end{tabular}

\section{Prediction of lymph node metastases}

The lymph nodes (LN) of 51 patients were assessed by histopathology and $n=31$ were node-positive. LN metastases were found on histopathology in 9 of 10 women with the CT parameter suprarenal LN> $1 \mathrm{~cm}$. The sensitivity, specificity, PPV and NPV were $29 \%$ (95\% Cl 14.2-48), 94.7\% (95\% Cl 74-99.9), 90\% (95\% Cl 55.398.5) and $45 \%$ (95\% Cl 39.3-68.2). In 11 of 12 patients with infrarenal LN $>2 \mathrm{~cm}$ in the CT LN metastases were found on histopathology, equivalent to a PPV of $91.7 \%$ (95\% Cl 60.6-99). The sensitivity, specificity and NPV of the parameter were $35.5 \%(95 \% \mathrm{Cl}$ 19.2-54.6), 95\% (95\% Cl 75.1-99.9) and 48.7\% (95\% Cl 41.8$55.7)$.

\section{Discussion}

The predictive value of preoperative CT of the abdomen in the evaluation of suboptimal cytoreduction in patients with advanced ovarian cancer was the object of this study as patients with no macroscopic tumour have a better prognosis than patients with residual tumour $\leq 1 \mathrm{~cm}$ and residual tumour $>1 \mathrm{~cm}[2,20]$. The aim of no macroscopic tumour and therefore an improvement in overall survival was achieved in $37.3 \%$ of women with FIGO stage IIC-IV ovarian cancer. In a retrospective analysis of three studies by the Gynecologic Oncology Group (GOG) of 1895 patients with FIGO stage III, Winter et al. (2007) reported that $23.1 \%$ had no macroscopic tumour. In a meta-analysis of the Cochrane database 11 studies were evaluated with regard to the prognostic influence of postoperative residual tumour. Only six studies contained information about the percentage of patients with no macroscopic tumour and this varied between 28.1 and $86 \%$ [21]. Harter et al. showed that by introducing structured quality management the proportion of patients with no macroscopic tumour was increased from $33 \%$ up to the year 2000 to $62 \%$ between $2004-2008$, which was reflected in a significant prolongation of median overall survival from 26 months to 45 months [22]. On the other hand, analysis of a multicentre study of advanced ovarian cancer (GOG 182, $\mathrm{n}=2655$ ) demonstrated that not all patients benefited from a radical operation with the outcome of no macroscopic tumour. Patients with a high tumour burden initially $(n=199)$ had significantly worse median disease-free survival (18.3 vs. 33.2 months; $p<0.001)$ and overall survival (50.1 vs. 82.8 months; $p<0.001)$ compared with patients with a low to medium tumour burden $(n=661)$ despite complete tumour resection. The authors pointed out the greater postoperative morbidity after complex surgical procedures and concluded that patients with a large initial tumour burden in whom the aim of no macroscopic tumour can be achieved only with high operative risk would benefit more from neoadjuvant chemotherapy [23]. The non-inferiority of primary chemotherapy compared with primary surgical cytoreduction was confirmed in a randomised study by the European Organisation for Research and Treatment of Cancer (EORTC). In this study, patients with stage IIIC and IV ovarian cancer were randomised to two arms, 
1. Primary operation, followed by six cycles of platinum-containing chemotherapy or

2. Three cycles of primary chemotherapy, followed by surgery and three more cycles of chemotherapy.

The proportion of patients with no macroscopic tumour was much lower with primary surgery than after neoadjuvant chemotherapy (19.4 vs. 51.2\%), but the groups did not differ with regard to the primary endpoints overall survival and recurrence-free survival [3]. Comparable results were also delivered by the prospective randomised non-inferiority CHORUS study with 552 patients with stage III and IV disease, conducted in the UK and New Zealand, in which the median survival after primary operation was 22.6 vs. 24.1 months after neoadjuvant PCT [5]. Based on these studies, the American Society of Clinical Oncology (ASCO) recommended initial evaluation by a gynaecologic oncologist including the preoperative $\mathrm{CT}$ of abdomen and pelvis and thorax in women with suspected ovarian cancer of FIGO stage IIIC or IV. Women with a high perioperative risk or low probability of optimal cytoreduction (residual tumour $<1 \mathrm{~cm}$, ideally no residual tumour) should receive neoadjuvant chemotherapy. If optimal cytoreduction (macroscopic freedom from tumour as far as possible) is probable with acceptable perioperative morbidity, primary operative therapy should be favoured [24].

With regard to the endpoint suboptimal tumour resection (residual tumour $>1 \mathrm{~cm}$ ), the finding of intraparenchymal liver metastases was the only independent predictive parameter. In previous studies, different models were tested for predicting suboptimal tumour resection by $\mathrm{CT}$, some of which also considered clinical and histopathological parameters [12-16, 18, 25-29]. While the different models in the predominantly single-centre retrospective studies could predict suboptimal tumour resection with a sensitivity and specificity each over $80 \%$, confirmation by crossvalidation at other institutions or in their own subsequent cohorts was mostly lacking $[17,18]$. Only Borley et al. (2014) successfully demonstrated the predictive value of a score they developed in a validation set with 70 patients [30]. This study included the CT parameters lung metastases, pleural effusions and tumour metastases $>10 \mathrm{~mm}$ in the mesentery of the small and large bowel as well as infrarenal para-aortic lymph nodes in the predictive model. However, the diagnostic validity of the scores was only moderate (AUC 0.721 ; 95\% Cl $0.594-0.847$ ) with a sensitivity of $64.7 \%$ and specificity of $67.9 \%$. In our study, the sensitivity of the parameter intraparenchymal liver metastasis was very low at $37.5 \%$ though the specificity was high at $89.7 \%$ with a positive predictive value of $66.7 \%$. This means that of 10 patients with preoperative evidence of intraparenchymal liver metastases in the $\mathrm{CT}$, roughly seven women have suboptimal tumour reduction but optimal debulking is possible in three patients.

Since the prognostic survival advantages is evident when macroscopic freedom from tumour is achieved [31], more recent studies have defined this as the aim of debulking surgery. Our results show that various $\mathrm{CT}$ parameters correlate significantly with the presence of macroscopic residual tumour, including diaphragm metastases $>2 \mathrm{~cm}$, mesocolon metastases, involvement of the greater omentum, ascites and diffuse peritoneal thickening. However, no single CT parameter was identified as an inde- pendent factor whereas aggressive tumour biology (high-grade serous papillary $\mathrm{OC}$ ) indicated incomplete tumour resection. On the other hand, patients with low-grade serous papillary $\mathrm{OC}$ also benefited from complete tumour resection [32].

In our study diffuse peritoneal thickening in particular correlated with macroscopic residual tumour (OR 6.7; $p<0.001$ ). However, 10 of 47 patients with this CT parameter had no macroscopic residual tumour and the residual tumour was $>10 \mathrm{~mm}$ in only 12 patients. Borley et al. (2014) also applied their score to the endpoint complete tumour resection vs. residual tumour $\geq 1 \mathrm{~mm}$ and showed a sensitivity of $50 \%$ with a specificity of $68.4 \%$ in the validation set [30]. A recently published study by Chesnais et al. (2017) with the endpoint of macroscopic residual tumour included, besides imaging findings, clinical parameters such as age, weight and paraclinical findings such as CA 12-5 and serum albumin in their analysis of 251 ovarian cancers, 196 with stage III and IV. They established a 100-point score, consisting of the parameters BMI, CA 12-5, CT evidence of tumour in the diaphragm and/or omentum and evidence of parenchymal metastases on positron emission tomography (PET), and used this score to divide patients into three groups: low risk (primary cytoreduction), medium risk (evaluation by laparoscopy) and high risk (neoadjuvant chemotherapy). In patients with advanced ovarian cancer (FIGO stage IIIC-IV, $\mathrm{n}=167$ ) the probability of incomplete cytoreduction in the high-risk group was $89.5 \%(77 / 86 ; 95 \% \mathrm{Cl}$ 81.3-94.4). Only six patients were assigned to the low-risk group, however, and three of them had complete tumour reduction [28]. Interestingly, in our study, clinical parameters such as age, BMI, Karnofsky index and ASA stage had no influence on operability.

Other imaging modalities such as PET-CT and magnetic resonance imaging (MRI) may be of benefit in predicting lymph node metastases (PET-CT) and local tumour spread in the pelvis (MRI), but studies currently do not justify their routine use in staging ovarian cancer [8].

In a comprehensive review that included different definitions of the endpoint optimal tumour reduction, Gomez-Hidalgo et al. (2015) contrasted various imaging studies with those of staging laparoscopy [33]. The rationale for primary laparoscopy is the possibility of obtaining tissue for histological and molecular genetic tests and in the identification of patients in whom optimal tumour reduction is not possible and who will therefore benefit from neoadjuvant chemotherapy. Fagotti et al. showed for the first time in 2005 that laparoscopy can predict optimal cytoreduction with an accuracy of $90 \%$ and demonstrated the superiority of laparoscopy when compared with clinical radiological findings in the negative predictive value (100 vs. $73 \%$ ) [34]. In subsequent studies, the same team established a laparoscopic score for predicting suboptimal tumour reduction and confirmed its validity in prospective single-centre and multicentre studies $[35,36]$. In a recent Cochrane analysis, the validity of laparoscopy in predicting optimal tumour reduction (no macroscopic residual tumour or residual tumour $\leq 1 \mathrm{~cm}$ ) was investigated. In the included 18 studies, between 16 and $73 \%$ of the women were assessed laparoscopically as not optimally resectable. Optimal tumour reduction was predicted for the remaining 27 to $84 \%$. In the subsequent debulking operation residual tumours $>1 \mathrm{~cm}$ remained in 0 to $31 \%$, i.e., these women could have been spared the primary operation. A 
pooled analysis was not possible because of the heterogeneity of the data. Only two of the 18 studies included information on the false-positive rate, that is, laparoscopic assessment of suboptimal tumour reduction was followed by debulking surgery with resulting residual tumour $\leq 1 \mathrm{~cm}$ [37].

New importance is attached to the preoperative assessment of pelvic and para-aortic node status as a result of the recently published LION study [19]. According to this, patients with advanced ovarian cancer and clinically and radiologically unremarkable nodal status do not benefit from systematic lymphadenectomy. According to our study, however, the negative predictive value of the CT with regard to nodal status is similarly low as in the recent retrospective analysis by Widschwendter et al. (2020) [38]. However, we found a high positive predictive value of over $90 \%$, i.e., the finding of enlarged LN in the CT could be relevant for preoperative (up-)staging of early tumour stages and thus for treatment planning.

The limits of the present study are the retrospective study design. The case number was reduced markedly by the lack of a preoperative CT in 20 patients. Besides the lower statistical power, this also signifies the risk of bias through selection of patients with particularly good or poor operability. The strengths are the blinded review of the CT scans by an oncological radiologist and that the study was conducted in a large gynaecologic oncology centre. Along with a high number of patients, the quality of treatment is reflected in the 5-year survival rates, which are comparable with those of other centres.

\section{Conclusion}

Our study emphasises the necessity in advanced ovarian cancer of resecting the tumour as completely as possible. Prediction of incomplete tumour resection is not always possible with certainty by imaging methods. However, various CT parameters such as extensive tumour metastases in the diaphragm and/or root of the mesentery, intraparenchymal liver metastases as well as diffuse peritoneal thickening indicate suboptimal tumour reduction and justify explorative laparoscopy with the possibility of continuing as debulking surgery. Ultimately, the assessment of operability is dependent to a high degree on the surgeon's expertise, so treatment at a certified gynaecologic oncology centre is necessary.

\section{Acknowledgements}

The authors are indebted to Dr. Jens Voigt, radiologist, for skillful review of the computed tomograms. They also wish to thank Prof. Günther Kundt of the Institute of Biostatistics and Informatics in Medicine, University of Rostock for his generous advice on statistical analyses.

\section{Conflict of Interest}

The authors declare that they have no conflict of interest.

\section{References}

[1] Robert Koch-Institut. Krebs in Deutschland für 2015/2016. Berlin: Robert Koch-Institut; 2019

[2] du Bois A, Reuss A, Pujade-Lauraine E et al. Role of surgical outcome as prognostic factor in advanced epithelial ovarian cancer: a combined exploratory analysis of 3 prospectively randomized phase 3 multicenter trials: by the Arbeitsgemeinschaft Gynaekologische Onkologie Studiengruppe Ovarialkarzinom (AGO-OVAR) and the Groupe d'Investigateurs Nationaux Pour les Etudes des Cancers de l'Ovaire (GINECO). Cancer 2009; 115: 1234-1244

[3] Vergote I, Tropé CG, Amant F et al. Neoadjuvant chemotherapy or primary surgery in stage IIIC or IV ovarian cancer. N Engl J Med 2010; 363: 943-953

[4] Tangjitgamol S, Manusirivithaya S, Laopaiboon M et al. Interval debulking surgery for advanced epithelial ovarian cancer. Cochrane Database Syst Rev 2013; (4): CD006014. doi:10.1002/14651858.CD006014.pub6

[5] Kehoe S, Hook J, Nankivell M et al. Primary chemotherapy versus primary surgery for newly diagnosed advanced ovarian cancer (CHORUS): an open-label, randomised, controlled, non-inferiority trial. Lancet 2015; 386: $249-257$

[6] Onda T, Satoh T, Ogawa G et al. Comparison of survival between primary debulking surgery and neoadjuvant chemotherapy for stage III/IV ovarian, tubal and peritoneal cancers in phase III randomised trial. Eur J Cancer 2020; 130: 114-125

[7] Fagotti A, Ferrandina G, Vizzielli G et al. Phase III randomised clinical trial comparing primary surgery versus neoadjuvant chemotherapy in advanced epithelial ovarian cancer with high tumour load (SCORPION trial): Final analysis of peri-operative outcome. Eur J Cancer 2016; 59 : 22-33

[8] Leitlinienprogramm-Onkologie. Leitlinien/Ovarialkarzinom. 01/2019. ed: AWMF. 2019. Online: https://www.awmf.org/uploads/tx_szleitlinien /032-035OLI_S3_Ovarialkarzinom_2020-04.pdf; last access: 31.03 .2020

[9] Du Bois AJS, Vergote I, Ferron G et al. Randomized phase III study to evaluate the impact of secondary cytoreductive surgery in recurrent ovarian cancer: Final analysis of AGO DESKTOP III/ENGOT-ov20. J Clin Oncol 2020; 38 (Suppl.): Abstr. 6000. doi:10.1200/JCO.2020.38.15_ suppl.6000

[10] Nam EJ, Yun M], Oh YT et al. Diagnosis and staging of primary ovarian cancer: correlation between PET/CT, Doppler US, and CT or MRI. Gynecol Oncol 2010; 116: 389-394

[11] Yuan Y, Gu ZX, Tao XF et al. Computer tomography, magnetic resonance imaging, and positron emission tomography or positron emission tomography/computer tomography for detection of metastatic lymph nodes in patients with ovarian cancer: a meta-analysis. Eur J Radiol 2012; 81: 1002-1006

[12] Byrom J, Widjaja E, Redman CW et al. Can pre-operative computed tomography predict resectability of ovarian carcinoma at primary laparotomy? BJOG 2002; 109: 369-375

[13] Bristow RE, Duska LR, Lambrou NC et al. A model for predicting surgical outcome in patients with advanced ovarian carcinoma using computed tomography. Cancer 2000; 89: 1532-1540

[14] Nelson BE, Rosenfield AT, Schwartz PE. Preoperative abdominopelvic computed tomographic prediction of optimal cytoreduction in epithelial ovarian carcinoma. J Clin Oncol 1993; 11: 166-172

[15] Dowdy SC, Mullany SA, Brandt KR et al. The utility of computed tomography scans in predicting suboptimal cytoreductive surgery in women with advanced ovarian carcinoma. Cancer 2004; 101: 346-352

[16] Jung DC, Kang S, Kim MJ et al. Multidetector CT predictors of incomplete resection in primary cytoreduction of patients with advanced ovarian cancer. Eur Radiol 2010; 20: 100-107 
[17] Gemer O, Gdalevich M, Ravid M et al. A multicenter validation of computerized tomography models as predictors of non-optimal primary cytoreduction of advanced epithelial ovarian cancer. Eur J Surg Oncol 2009; 35: 1109-1112

[18] Axtell AE, Lee MH, Bristow RE et al. Multi-institutional reciprocal validation study of computed tomography predictors of suboptimal primary cytoreduction in patients with advanced ovarian cancer. J Clin Oncol 2007; 25: 384-389

[19] Harter P, Sehouli J, Lorusso D et al. A Randomized Trial of Lymphadenectomy in Patients with Advanced Ovarian Neoplasms. N Engl J Med 2019; 380: $822-832$

[20] Winter WE 3rd, Maxwell GL, Tian C et al. Prognostic factors for stage III epithelial ovarian cancer: a Gynecologic Oncology Group Study. J Clin Oncol 2007; 25: 3621-3627

[21] Elattar A, Bryant A, Winter-Roach BA et al. Optimal primary surgical treatment for advanced epithelial ovarian cancer. Cochrane Database Syst Rev 2011; (8): CD007565

[22] Harter P, Muallem ZM, Buhrmann C et al. Impact of a structured quality management program on surgical outcome in primary advanced ovarian cancer. Gynecol Oncol 2011; 121: 615-619

[23] Horowitz NS, Miller A, Rungruang B et al. Does aggressive surgery improve outcomes? Interaction between preoperative disease burden and complex surgery in patients with advanced-stage ovarian cancer: an analysis of GOG 182. J Clin Oncol 2015; 33: 937-943

[24] Wright AA, Bohlke K, Armstrong DK et al. Neoadjuvant Chemotherapy for Newly Diagnosed, Advanced Ovarian Cancer: Society of Gynecologic Oncology and American Society of Clinical Oncology Clinical Practice Guideline. J Clin Oncol 2016; 34: 3460-3473

[25] Meyer JI, Kennedy AW, Friedman R et al. Ovarian carcinoma: value of CT in predicting success of debulking surgery. AJR Am J Roentgenol 1995; 165: $875-878$

[26] Qayyum A, Coakley FV, Westphalen AC et al. Role of CT and MR imaging in predicting optimal cytoreduction of newly diagnosed primary epithelial ovarian cancer. Gynecol Oncol 2005; 96: 301-306

[27] Kebapci M, Akca AK, Yalcin OT et al. Prediction of suboptimal cytoreduction of epithelial ovarian carcinoma by preoperative computed tomography. Eur J Gynaecol Oncol 2010; 31: 44-49
[28] Chesnais M, Lecuru F, Mimouni M et al. A pre-operative predictive score to evaluate the feasibility of complete cytoreductive surgery in patients with epithelial ovarian cancer. PLoS One 2017; 12: e0187245

[29] Ferrandina G, Sallustio G, Fagotti A et al. Role of CT scan-based and clinical evaluation in the preoperative prediction of optimal cytoreduction in advanced ovarian cancer: a prospective trial. $\mathrm{Br}$ J Cancer 2009; 101: 1066-1073

[30] Borley J, Wilhelm-Benartzi C, Yazbek J et al. Radiological predictors of cytoreductive outcomes in patients with advanced ovarian cancer. BJOG 2015; $122: 843-849$

[31] Chang SJ, Hodeib M, Chang J et al. Survival impact of complete cytoreduction to no gross residual disease for advanced-stage ovarian cancer: a meta-analysis. Gynecol Oncol 2013; 130: 493-498

[32] Ricciardi E, Baert T, Ataseven B et al. Low-grade Serous Ovarian Carcinoma. Geburtshilfe Frauenheilkd 2018; 78: 972-976

[33] Gómez-Hidalgo NR, Martinez-Cannon BA, Nick AM et al. Predictors of optimal cytoreduction in patients with newly diagnosed advanced-stage epithelial ovarian cancer: Time to incorporate laparoscopic assessment into the standard of care. Gynecol Oncol 2015; 137: 553-558

[34] Fagotti A, Fanfani F, Ludovisi M et al. Role of laparoscopy to assess the chance of optimal cytoreductive surgery in advanced ovarian cancer: a pilot study. Gynecol Oncol 2005; 96: 729-735

[35] Fagotti A, Ferrandina G, Fanfani F et al. Prospective validation of a laparoscopic predictive model for optimal cytoreduction in advanced ovarian carcinoma. Am J Obstet Gynecol 2008; 199: 642.e1-642.e6

[36] Fagotti A, Vizzielli G, De laco P et al. A multicentric trial (Olympia-MITO 13 ) on the accuracy of laparoscopy to assess peritoneal spread in ovarian cancer. Am J Obstet Gynecol 2013; 209: 462.e1-462.e11

[37] van de Vrie R, Rutten MJ, Asseler JD et al. Laparoscopy for diagnosing resectability of disease in women with advanced ovarian cancer. Cochrane Database Syst Rev 2019; (3): CD009786

[38] Widschwendter P, Blersch A, Friedl TWP et al. CT Scan in the Prediction of Lymph Node Involvement in Ovarian Cancer - a Retrospective Analysis of a Tertiary Gyneco-Oncological Unit. Geburtshilfe Frauenheilkd 2020; 80: 518-525 